\title{
RADIKALISME AGAMA DALAM PERSPEKTIF PENDIDIKAN
}

\author{
Hujair AH Sanaky \\ Direktur Pascasarjana (PPs) Fakultas Ilmu Agama Islam UII dan \\ Dosen tetap FIAI UII Program Studi Pendidikan Islam \\ email: hujair.alhau@gmail.com
}

\section{Edy Safitri}

Pusat Studi Islam, Universitas Islam Indonesia

email: edy_pasca@yahoo.com

\section{Abstract}

Indonesia is a pluralistic society, it is necessary that education should provide an overview and moral ideals of religion contextually. In the educational process required a review of the religious doctrines, like the doctrine of jihad. That is, jihad is no longer understood as an endorsement of Islam to violence in spreading faith. The plurality of religion and belief is no longer understood as a potential riot, but be a potential to be invited to jointly implement the teachings for the sake of humanity. All religions should claim peace and human safety. In this context, education has an important role to foster self-scratch, so not only can receive others, but also able to work with different beliefs or religion. This means that education should enable the growth of the brotherhood in unity, so as to jointly build a new world that is more meaningful for all of humanity. So that, design education should accommodate pluralist and tolerant. Attitude required teachers of religion that is tolerant and pluralist.
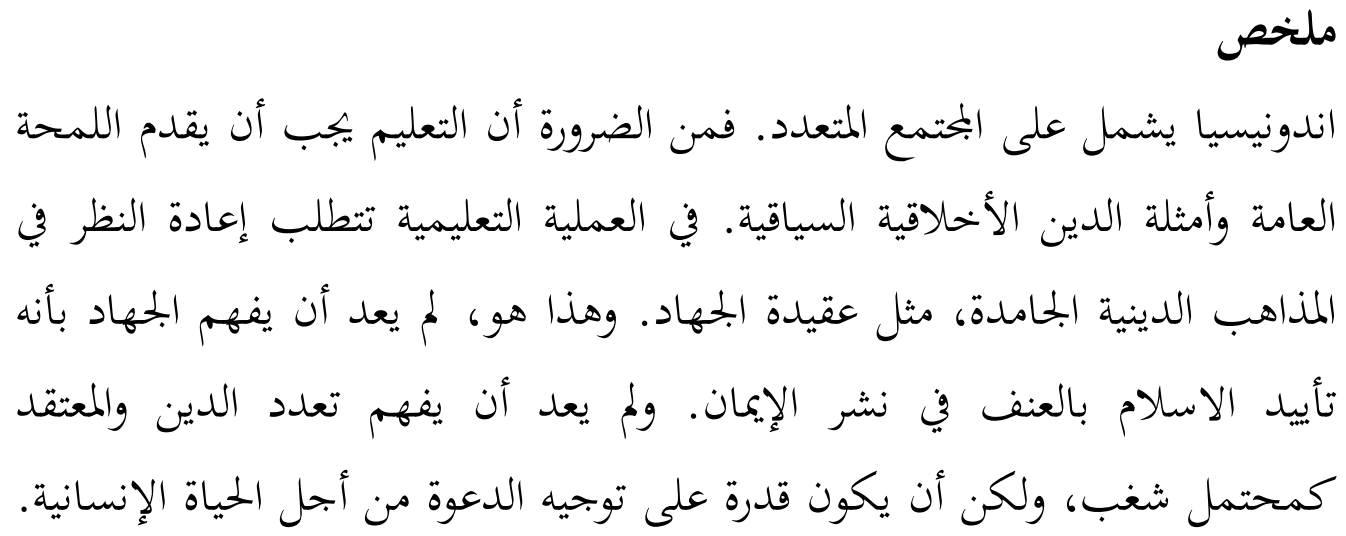


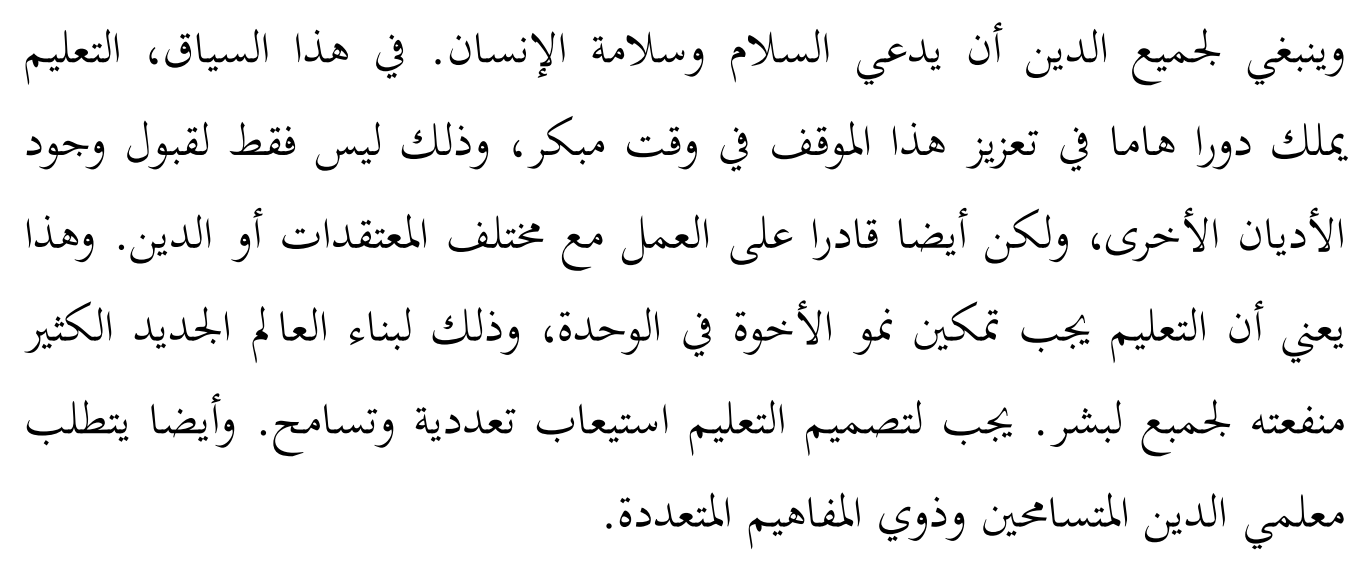

Keywords: Pendidikan yang humanis.

\section{A. Pendahuluan}

Era reformasi ditandai dengan tergulingnya reszim pemerintahan Soeharto, dibarengi dengan krisis moneter, ekonomi, dan politik telah mendorong arus pembaruan dalam semua aspek kehidupan. Pembaruan dan reformasi ${ }^{1}$ telah menggerakkan perubahan dalam semua aspek kehidupan, bahkan berdampak pada euforia ${ }^{2}$ kebebasan yang nyaris kebablasan. ${ }^{3}$ Era reformasi, selain mem-

1 Reformasi muncul dengan berbagai penafsiran mengenai arti reformasi seperti antara lain yang dikemukakan oleh Emil Salim dan Din Syamsuddin dalam polemik perumusannya. Emil Salim menekankan arti reformasi untuk perubahan dengan melihat keperluan masa depan. Din Syamsuddin menekankan kepada kembali dalam bentuk asal. Tilaar mengatakan bahwa kedua penafsiran reformasi tersebut sah-sah saja, karena keduanya menginginkan perubahan. Tilaar menggunakan definisi kerja mengenai reformasi sebagai "to make better by putting a stop to abuses or malpractices or by introducing better procedures". Di dalam definisi ini ditunjukkan perlu adanya suatu perombakan menyeluruh dari suatu sistem kehidupan dalam aspek-aspek politik, ekonomi, hukum, juga termasuk pendidikan. H.A.R. Tilaar, Beberapa Agenda Reformasi Pendidikan Nasional Dalam Perspektif Abad 21 (Magelang: Tera Indonesia, 1998), hal. 25.

2 Euforia demokrasi yang sedang marak dalam masyarakat melahirkan berbagai pemikiran, pendapat, pandangan, dan konsep mengenai bentuk masyarakat dan bangsa Indonesia yang dicita-citakan di masa depan, tetapi kadang-kadang satu sama lain bertentangan. H.A.R. Tilaar, Pendidikan, Kebudayaan, dan Masyarakat Madani Indonesia: Strategi Reformasi Pendidikan Nasional, (Bandung: Remaja Rosdakarya, 1999), hal. 3. Untuk membangun suatu masyarakat yang disebut dengan "masyarakat madani" atau sering juga disebut dengan istilah masyarakat "Indonesia Baru," sebagai ciri dari masyarakat demokrasi.

3 "Kebablasan" diartikan atau dikonotasikan dengan "kebebasan tanpa aturan". Azyumardi Azra menyatakan sekarang ini di kalangan masyarakat semakin berkembang 
berikan harapan besar hadirnya kebebasan, keamanan, dan kenyaman untuk hidup di bumi pertiwi Indonesia ini, namun di sisi lain, era ini oleh kelompok keagamaan tertentu justru dijadikan momentum emas untuk mendorong bangkitnya radikalisme agama yang berujung aksi-aksi kekerasan dan terorisme berbasiskan agama. Sebagai refleksi, mulai dari kasus bom Bali I, bom bali II, bom kedutaan Besar Australia, bom Hotel Mariot I, Bom Hotel mariot II, Bom Hotel Ritz Carlton, Bom buku yang disasarkan ke sejumlah figur, Bom jum'at di masjid Maporles Cirebon, dan bom bunuh diri di gereja Bethel Injil Sepenuh (GBIS) Kepunton, Solo.

Selain itu aksi-aksi radikalisme agama juga tidak kalah merebaknya di era reformasi ini. Sebut saja di antaranya, penyerbuan kampus Al-Mubarok, Ahmadiyah di Parung, Jemaat Ahmadiyah di Cikeussik, Pandeglang, Banten, penutupan rumah ibadah kristiani di bandung Jawa Barat, dan terakhir masuknya gerakan radikalisme yang mengatasnamakan Islamic State Of Iraq and Syiria (ISIS). Lebih ironis, dari pelaku baik yang tertangkap ataupun terbunuh oleh Densus 88, justru dari kalangan muda muslim usia sekolah. Berbagai kasus di atas, mencitrakan Islam sebagai agama yang rahmatan lil'alamin, tentu bukanlah persoalan yang mudah.

Radikalisme itu sendiri merupakan suatu paham yang menghendaki adanya perubahan, pergantian, dan penjebolan terhadap suatu sistem di masyarakat sampai ke akar-akarnya. Jika perlu perubahan tersebut dilakukan dengan cara kekerasan. Bagi kaum radikal ini, bahwa rencana-rencana yang digunakan merupakan rencana-rencana yang ideal. ${ }^{4}$ Radikalisme seringkali beralaskan pemahaman sempit agama yang berujung pada aksi teror bom tumbuh bersama sistem. Dan sikap ekstrim ini berkembang biak dan menguat di tengah-tengah panggung yang mempertontonkan kemiskinan, kesenjangan sosial, atau ketidakadilan sosial. Prilaku elit politik yang tidak akomudatif terhadap kepentingan rakyat dan hanya memikirkan kelompok dan partainya

\footnotetext{
"kelatahan sosial" seperti tuntutan demokrasi yang diartikan sebagai "kebebasan tanpa aturan," tuntutan otonomi sebagai kemandirian tanpa kerangka acuan dan tuntutan hak asasi manusia yang mendahulukan hak tanpa memperhatikan kewajiban, pada akhirnya berkembang ke arah berlakunya hukum rimba yang memicu kesukubangsaan (ethnicity). Azyumardi Azra, Paradigma Baru Pendidikan Nasional: Rekonstruksi dan Demokratisasi (Jakarta: Penerbit Buku Kompas, 2002), hal. xiv.

4 Pior Stompka, Sosiologi Perubahan Sosial, (Jakarta: Kencana Prenanda Media Group, 2009), hal.223
} 
menjadi tempat dan persemaian subur bagi tumbuhnya radikalisme. ${ }^{5}$

Dengan demikian radikalisme atau bahkan terorisme, tidak hanya gerakan sosial semata, namun juga gerakan ideologis. Idiologi tidak mungkin dapat dibasmi hanya dengan pendekatan militer saja. Namun dibutuhkan berbagai pendekatan lainnya. Salah satunya pendekatan pendidikan. Problemnya adalah dunia pendidikan kita, khususnya pendidikan agama (Islam) sampai hari ini masih dianggap menjadi bagian dari persoalan ketimbang bagian dari solusi.

\section{B. Dunia Pendidikan Menjadi Tertuduh}

Pendidikan merupakan proses di mana bangsa mempersiapkan generasi mudanya untuk menjalankan kehidupannya. Pendidikan merupakan proses menaburkan benih-benih budaya dan perdaban manusia yang hidup dan dihidupi oleh nilai-nilai atau visi yang berkembang dan dikembangkan di dalam suatu masyarakat. Inilah pendidikan sebagai suatu proses pembudayaan. ${ }^{6}$ Berarti pendidikan berfungsi mengembangkan kemampuan dan membentuk watak serta peradaban bangsa yang bermartabat dalam rangka mencerdaskan kehidupan bangsa. Bertujuan untuk berkembangnya potensi peserta didik agar menjadi manusia yang beriman dan bertakwa kepada Tuhan Yang Maha Esa, berakhlak mulia, sehat, berilmu, cakap, kreatif, mandiri, dan menjadi warga negara yang demokratis serta bertanggung jawab.

Idealnya dunia pendidikan khususnya pendidikan agama Islam menjadi solusi ampuh dan jitu untuk meredam berbagai aksi kekerasan berbasiskan agama. Pendidikan dianggap memiliki peran yang luhur dan agung. Pendidikan juga dipahami sebagai sarana efektif dalam memberikan berbagai bekal kehidupan bagi peserta didik, sarana mencerdaskan individu masyarakat, negara dan bangsa. Ini berati dalam relasi antar agama, khususnya nilai-nilai kedamaian, toleransi, inklusif dan keharmonisan dapat ditanamkan pada generasi muda bangsa melalui pendidikan. Pendidikan menjadi "panglima" dalam membentuk peradaban bangsa.

5 Zuly Qodir, Deradikalisasi Islam dalam Perspektif Pendidikan Agama) dalam Jurnal Pendidikan Agama Islam, Volume II, Nomor 1, Juni 2013.

6 H.A.R. Tilaar, Pendidikan, Kebudayaan, dan Masyarakat Madani Indonesia, (Bandung: Remaja Rosdakarya, 1999), hal.9. 
Ironisnya, faktanya justru sebaliknya, lembaga pendidikan justru diposisikan sebagai "tertuduh" utama penyebab terjadinya berbagai kasus kekerasan atas nama agama di tengah masyarakat. Pendidikan Agama Islam dituding menjadi mesin pencetak intoleransi, radikalisme dan terorisme pada peserta didik. Banyaknya pelaku terorisme dan radikalisme Islam yang melibatkan kaum muda terpelajar, baik pelajar, mahasiswa maupun lulusan perguruan tinggi menjadi penguat dari berbagai tuduhan minor di atas.

Indikasi lainnya, munculnya gerakan sistematis yang dilakukan oleh kelompok-kelompok keagamaan tertentu untuk mengajarkan doktrin keagamaan garis keras di kalangan pelajar Sekolah Menengah Atas (SMA). ${ }^{7}$ Hasil riset tentang politik Ruang Publik Sekolah yang dilakukan Hairus Salim memperkuat sinyalemen tersebut. Dalam riset yang dilakukan, Salim menyimpulkan bahwa ada upaya-upaya menjadikan sekolah yang seharusnya menjadi ruang publik yang bebas untuk semua golongan siswa, ditafsirkan dan dibentuk berdasarkan paham dan kepentingan satu golongan saja. ${ }^{8}$

\section{Deradikalisasi Guru Agama Mendesak Dilakukan}

Meskipun faktor lahirnya aksi-aksi terorisme dan radikalisme sangatlah kompleks, namun maraknya fenomena kekerasan mengatasnamakan agama terlebih dilakukan oleh para pelaku dari kalangan muda usia sekolah, maka fenomena tersebut seharusnya menjadi catatan tersendiri bagi penyelengaraan PAI di Indonesia selama ini. Harus diakui pendidikan agama selama ini tidak berdaya melakukan penanaman nilai-nilai universal keagamaan, seperti kemajemukan/pluralitas, toleransi kemanusiaan dan sebagainya. Pelajaran agama yang diajarkan di lembaga pendidikan oleh banyak pihak dianggap lebih banyak bersifat ritual dan dogmatik.

Selain itujuga masih berkutat pada persoalan hukum-hukum, aturanatauran, larangan-larangan. Pelajaran agama kurang menyentuh hal yang sangat mendasar yang berkaitan dengan persoalan iman, harapan dan kasih sayang. Tekanan pengajaran agama masih terletak pada to have religion,

7 Indriyani Ma'rifah, Rekonstruksi Pendidikan Agama Islam: Sebuah Upaya Membangun Kesadaran untuk Mereduksi Terorisme dan Radilasime Islam, hal. 241.

8 Selengkapnya bisa dibaca dalam Hairus Salim HS dkk, Politik Ruang Publik Sekolah: Negosiasi dan Resistensi di SMUN di Yogyakarta, (Jogjalarta; CRCS, 2011) 
bukannya pada to be religion. Menekankan pada kesalehan individual daripada kesalehan sosial. Pendeknya pelajaran agama belum menyentuh hal-hal mendasar bagi keberlangsungan kehidupan umat manusia. Lebih khusus keberlangsungan kehidupan umat dalam konteks kemajemukan bangsa. Dan ketika kegelisahan terkait problem tersebut mencuat dipermukaan, solusi yang ditawarkan biasanya adalah melakukan deradikalisasi pendidikan agama Islam yang menitik beratkan pada redesign kurikulum pendidikan agama Islam yang berperspektif pluralis atau multikultural.

Menitikberatkan perhatian deradikalisasiPAIlewatpembenahankurikulum tentu tidaklah salah. Kurikulum, sebagaimana dikemukakan Nana Syaodih Sukmadinata, mempunyai posisi sentral dalam seluruh proses pendidikan. Kurikulum mengarahkan segala bentuk aktivitas pendidikan dalam rangka mencapai tujuan-tujuan pendidikan. Selain itu kurikulum juga merupakan suatu rencana pendidikan yang memberikan pedoman dan pegangan tentang jenis, lingkup urutan isi dan proses pendidikan. Kurikulum bukan sekadar rencana tertulis bagi pengajaran tetapi juga sesuatu yang fungsional yang beroprasi dalam kelas, yang membeir pedoman dan mengatur lingkungan dan kegiatan yang berlangsung di dalam kelas. ${ }^{9}$ Karenanya perumusan kurikulum PAI untuk menyelesaikan maraknya radikalisme dan tindakan terorisme di kalangan muda usia sekolah merupakan langkah mendesak yang harus dilakukan.

Umat Islam sesungguhnya sudah menyadari bahwa untuk membangun peradaban umat masa depan, harus terlebih dahulu memperbaiki, memperjelas, dan mengukuhkan eksistensi lembaga pendidikan sebagai satu sarana utama dalam mewujudkan keinginan tersebut. Namun hingga saat ini usaha-usaha yang dilakukan baru sebatas mencari model pendidikan, dan model kurikulum yang islami. Hal ini tentunya karena lembaga pendidikan Islam yang sudah ada belum mampu memenuhi kreteria yang diinginkan umat dan belum memiliki model yang jelas. Sehingga antara label dan isi terdapat jurang pemisah yang sangat dalam. ${ }^{10}$

Terkait masalah redisain kurikulum berperspektif pluralis dipandang sebagai solusi yang mendesak dalam meminimalisir radikalisme dan terorisme

9 Dalam Indriyani Ma'rifah, Rekonstruksi ..,hal 5.

10 Amrullah Achmad dalam A. Syafii Maarif dkk, Pendidikan Islam di Indonesia; Antara Cita dan Fakta, (Yogyakarta: Tiara Wacana Yogja, 1991), hal. 109 
di kalangan muda di Indonesia, dalam pandangan penulis tidak akan efektif, tanpa menghadirkan guru yang pluralis pula. Guru yang notabenenya selaku pelaksana dan perancang pengajaran, keberadaannya jelas menjadi ujung tombak penyampai pesan-pesan kurikulum. Sayangnya aspek guru ini belum menjadi prioritas untuk dilakukan pembenahan. Bagaimana mungkin pendidikan agama yang ingklusif dan pluralis dapat terealisasi, jika gurunya ternyata tidak memiliki perspektif yang senada.

Pandangan yang menyatakan bahwa menyelesaikan persoalan radikalisme dan terorisme pada kalangan muda di sekolah atau lembaga perguruan tinggi, harus diawali dengan mendisain ulang kurikulum yang berperspektif pluralis dan multicultural telah mengandaikan bahwa selama ini kurikulum dalam proses pembelajaran sudah berperan sebagaimana mustinya. Padahal faktanya, antara kurikulum dan pendidik dalam praktiknya selama ini berjalan sendirisendiri, seolah tidaksaling berkait. Melihat realitas demikian, penulis sampai hari ini, secara ekstrim, masih meyakini, bahwa meskipun kurikulumnya didisain anti toleransi sekalipun tetapi, jika dijalankan oleh guru yang berpandangan pluralis, pesan-pesan yang disampaikan akan pluralis pula dan begitu pula sebaliknya. ${ }^{11}$

Karenanya saya berpandangan, fenomena menguatnya aksi-aksi radikalisme dan terorisme yang terus marak dan melibatkan kalangan muda sebagai pelaku, tidak bisa dilepaskan dari kontribusi para guru agamanya. Dalam hal ini menarik menyimak hasil survei yang dilakukan Lembaga Kajian Islam dan Perdamaian (LaKIP) UIN Syarif Hidayatullah, Jakarta.

Menurut survey yang dilakukan tahun 2010/2011 terhadap guru PAI dan murid SMP dan SMA di Jabodetabek ini menunjukkan sebanyak 62,4 persen guru agama -termasuk dari kalangan NU dan Muhammadiyah, menolak untuk

11 Dalam konteks ini penulis memiliki pengalaman empirik. Saat duduk di bangku Sekolah Dasar (SD) terdapat pelajaran Pendidikan Moral Pancasila (sekarang menjadi Pendikan kewarganegaraan). Dalam mata pelajaran tersebut diajarkan tentang kerukunan umat beragama. Meskipun pesan yang hendak disampaikan adalah tentang kerukunan antar umat beragama, bahkan dalam buku yang menjadi pegangan siswa secara jelas digambarkan kelima rumah ibadah (masjid, gereja, wihara dst), dan ditempatkan secara berdampingan yang tentunya dimaksudkan memberikan pesan kerukunan terhadap para peserta didik. Akan tetapi karena diampu oleh guru yang eksklusif justru pesan-pesan kerukunan tersebut tidak tersampaikan sama sekali. Yang terjadi justru guru tersebut mengajarkan berdasarkan subyektifitas keyakinannya. 
mengangkat pemimpin non-muslim. 68.6 persen guru agama menentang diangkatnya orang non- muslim sebagai kepala sekolah mereka. Presentase guru agama yang menolak kehadiran rumah ibadah non muslim di lingkungan mereka cukup besar, yakni 73, 1 persen. Sedangkan ada 85.6 persen guru agama yang melarang murid mereka untuk ikut merayakan apa yang dipersepsikan sebagai "tradisi Barat".

Demikian pula terdapat 87 persen yang menganjurkan muridnya untuk tidak mempelajari agama-agama lain dan 48 persen lainnya lebih menyukai pemisahan laki-laki dan perempuan dalam kelas yang berbeda. 75,4 persen dari responden yang meminta agar murid-murid mereka mengajak guru-guru nonmuslim untuk masuk Islam, sementara 61,1 persen menolak sekte baru dalam Islam. Sebanyak 67,4 persen responden yang lebih merasa sebagai muslim ketimbang sebagai orang Indonesia.

Lebih dari itu, mayoritas responden juga mendukung penerapan syariah Islam untuk mengurangi angka kriminalitas: 58,9 persen mendukung hukum rajam dan 47,5 persen mendukung hukum potong tangan untuk pencuri serta 21,3 persen setuju hukuman mati bagi orang murtad dari agama Islam. ${ }^{12}$ Membaca fakta tersebut di atas, sangat kecil kemungkinan mereka ini akan merujuk pada pedoman kurikulum yang tersedia. Yang terjadi, mereka akan meletakkan panduan kurikulum dalam laci meja dan mengajarkan materi pelajaran sesuai dengan subyektifitas keyakinan mereka. Relaitas demikian yang selasma ini berl;angsung dalam konteks pembelajaran agama di sekolahsekolah.

Tentunya banyak faktor yang memicu mengapa guru agama berperilaku anti pluralis. Bisa karena pemahaman individu guru, kurikulum, dan rendahnya dialog antar agama di kalangan masyarakat. Pandangan keagamaan para guru yang masih eksklusif ini sebagaimana dikemukakan data LaKIP ini tentu sangat memperihatinkan, lebih-lebih terjadi pada guru yang mengajar peserta didik di jenjang SMA/SMK yang merupakan salah satu fase yang mempunyai arti strategis bagi perkembangan siswa dari masa transisi remaja menuju dewasa.

Berangkat dari fakta di atas tidak sedikit yang kemudian berpandangan bahwa kecenderungan sikap keberagamaan masyarakat yang intoleran ini

12 Dalam http://www.detiknews.com/read/2011/04/28/205903/1628139/159/ini-diahasil-survei-lakip-yang-menghebohkan-itu?nd991107159. Di akses pada tanggal 3 Juli 2013. 
khususnya kalangan muda di Indonesia, di antaranya dipengaruhi pendidikan agama yang diajarkan di sekolah yang cenderung ekskulsif dan anti pluralis. Ada kecenderungan menguatnya sikap keberagamaan yang eksklusif justru diperoleh dari interaksi peserta didik dengan gurunya dalam pembelajaran di kelas atau interaksi mereka di lingkungan seklolah.

Hasil survey di atas, menunjukkan keterkaitan yang sangat kuat antara pandangan anti-pluralis para guru agama dengan prilaku keagamaan peserta didiknya. Paham-paham keagamaan para guru lebih terefleksikan dalam pelajaran mereka dan berkontribusi menumbuhkan konservatisme dan radikalisme agama di masyarakat, khususnya di kalangan muda. Karenanya penulis berpandangan, berbagai upaya deradikalisasi pendidikan Islam tidak akan bermakna signifikan atau bahkan sia-sia, jika tidak diimbangi dengan kesiapan guru agama (selaku pelaksana dan perancang pengajaran), baik pada aspek paradigma keagamaanya maupun metode pengajarannya; dari doktrinasi menuju dialogis.

Untuk menghadirkan gura agama yang berperspektif pluralis dan toleran, tentu dibutuhkan proses yang tidak sebentra, karena ini berkaitan dengan perubahan mindset. Namun dalam jangka pendek, menurut Ahmad Asroni sebagaimana dikutip Indriyani Ma'rifah, ada beberapa cara yang bisa ditempuh. Pertama, menyelenggrakan secara intens berbagai training, workshop, seminar dan kegiatan- kegiatan lainnya yang berwawasan multicultural, pluralis kepada para pendidik/guru agama. Kedua, menyelenggarakan dialog keagamaan dengan pendidik agama, pemuka atau umat beragama lainnya. Dengan demikian para pendidik agama Islam ini dan pendidik agama lain dapat berbaur dan mengenal satu sama lain. Sehingga pada gilirannya akan melahirkan sikap apresiatif dan toleran terhadap agama lain. Ketiga, memperkenalkan bahan bacaan atau berbagai refernsi yang bernuansa pendidikan multicultural sejak dini kepada para pendidik.

Jika kegiatan-kegiatan seperti ini dilakukan secara intens dan serius maka meskipun tidak mudah tapi memberikan ruang terjadinya perubahan maindset para guru; dari paham anti-pluralis menjadi pluralis dan toleran. 


\section{Penutup}

Dalam masyarakat yang sangat majemuk seperti Indonesia, pendidikan harus memberikan gambaran dan idealitas moral agamanya secara kontekstual. Di sini diperlukan dipersyaratkan peninjauan ulang atas doktrin-doktrin agama yang kaku dan keras, seperti halnya doktrin jihad. Dalam artian, jihad bukan lagi dipahami sebagai persetujuan Islam untuk menggunakan kekerasan dalam menyebarkan agama. Pluralitas agama dan keyakinan, tidak lagi dipahami sebagai potensi kerusuhan, melainkan menjadi potensi untuk diajak bersama melaksanakan ajaran demi kepentingan kemanusiaan dan peradaban manusia. Seluruh agama harus mengklaim demi perdamaian dan keselamatan manusia.

Di sini pendidikan memiliki peran penting menumbuhkan sikap awal agar tidak hanya bisa menerima keberdaan agama lain, tapi juga mampu bekerja sama dengan keyakinan ataun agama yang berbeda. Pendidikan harus memungkinkan tumbuhnya persaudaraan dalam kebersamaan tersebut, sehingga dapat bersama membangun dunia baru berperadaban yang lebih bermakna bagi seluruh umat manusia. Itu semua akan dapat terwujud, jika disain pendidikan agama Islam mengakomodasi pluralis dan toleran yang diimbangi dengan guru-guru agama yang toleran dan pluralis pula.

\section{DAFTAR PUSTAKA}

Achmad, Amrullah, dalam A. Syafii Maarif dkk, 1991, Pendidikan Islam di Indonesia; Antara Cita dan Fakta, Yogyakarta: Tiara Wacana Yogja.

Azra, Azyumardi, 2002, Paradigma Baru Pendidikan Nasional: Rekonstruksi dan Demokratisasi, Jakarta: Penerbit Buku Kompas, 2002.

http:/ / www.detiknews.com/read/2011/04/28/205903/1628139/159/inidia-hasil-survei-lakip-yang-menghebohkan-itu?nd991107159. Di akses pada tanggal 3 Juli 2013.

Ma'rifah, Indriyani, Rekonstruksi Pendidikan Agama Islam: Sebuah Upaya Membangun Kesadaran untuk Mereduksi Terorisme dan Radilasime Islam.

Stompka, Pior, 2009, Sosiologi Perubahan Sosial, Jakarta: Kencana Prenanda Media Group.

Qodir, Zuly, 2013, Deradikalisasi Islam dalam Perspektif Pendidikan Agama) dalam Jurnal Pendidikan Agama Islam, Deradikalisasi Pendidikan Islam,Volume II, Nomor 1, Juni 2013. 
Salim HS, Hairus, dkk, 2011, Politik Ruang Publik Sekolah: Negosiasi dan Resistensi di SMUN di Yogyakarta, Jogjalarta; CRCS.

Stompka, Pior, 2009, Sosiologi Perubahan Sosial, Jakarta: Kencana Prenanda Media Group.

Tilaar, H.A.R., 1998, Beberapa Agenda Reformasi Pendidikan Nasional Dalam Perspektif Abad 21, Magelang: Tera Indonesia. 1999, Pendidikan, Kebudayaan, dan Masyarakat Madani Indonesia, Bandung: Remaja Rosdakarya. 
